\title{
DETERMINATION OF WHEEL-RAIL CONTACT CHARACTERISTICS BY CREATING A SPECIAL PROGRAM FOR CALCULATION
}

IOAN SEBEȘAN - Professor Doctor Engineer, Department of Railway vehicles and rolling stocks, Faculty of Transport, Polytechnic University of Bucharest, e-mail: ioan_sebesan@yahoo.com

Yahia ZAKARIA - PhD. Student Engineer, Department of Railway vehicles and rolling stocks, Faculty of Transport, Polytechnic University of Bucharest,e-mail: sharkasianlion@yahoo.com

\begin{abstract}
The authors in this paper describe the steps of creating a special program in GUI tool in Matlab. The program is designed to calculate the main properties of wheel-rail contact zone, such as: contact ellipse dimensions, normal stress and friction coefficients. All the relevant equations, which were introduced by different researchers, are firstly presented and modified to be applicable to the programming environment, and then the program was built. In the end, the program working quality is discussed and some expected future developments on this program are suggested. The proposed program can make the comparison between theoretical and experimental results, when they are available, easier and faster.
\end{abstract}

Keywords: Matlab, GUI, railway, friction, contact ellipse, Kalker.

\section{Introduction}

The traction and braking forces on the railway vehicles are related to the characteristics of the contact zone between rails and wheels. The relations which determine these characteristics are numerous and difficult to be calculated manually, thing which makes it important to create a special computer program to put all the equations together and calculate them at once.

The researchers' efforts to create better programs to simulate wheel-rail contact are increasing day by day. CONTACT $[1,2,3]$, as an example of these programs, is a simulation program created specially to solve contact problems, which occur between wheel and rails, in roller bearings and in offset printing devices. It implements the theories for rolling contact by Vollebregt and Kalker. Another example of these programs is introduced by Jong Kim in [4]. Kim's program is a GUI ${ }^{1}$, which provides contact shape and normal pressure within contact ellipse between rail and wheel. The authors, in this paper, present a more developed version of Kim's program having the following features:

- The mathematical base is built using the most recent equations which describe the contact zone properties;

- The program is composed of two windows built in GUI tool in Matlab;

- The program calculates friction coefficients on both external and internal wheels using three different methods of calculation. It calculates contact ellipse dimensions and normal pressure in the contact zone for two different types of wheels, the wheels with conic profiles which can be found on locomotives, and the wheels with worn profiles which can be found on freight and passenger rail cars;

- The program has a dynamic structure, which can be easily developed by other users, due to its scientific background, which is provided in this paper.

\footnotetext{
${ }^{1}$ Graphical User Interface
} 
The details of creating the computer program in GUI and the gained results will be presented in this paper. Calculations based on theoretical equations might not give results coincident with the real situations. These results can be different from the results gained from the experiments, which are performed within the same essential conditions. Thus, the purpose of creating the program is to easily reach the results given by the theoretical equations and to easily modify the essential conditions. The experimental and the theoretical results, then, can be compared to determine how much the theoretical equations are close to reality. To simplify the building of the mathematical base, the relations introduced by Hertz [5, 6], Kalker [7, 8], Chartet [9] and Polach [10] will be used. The stages of creating the computer program in Matlab program are described in Fig. 1 and they are the following:

- The first step is to build the mathematical base. All the related relations are collected and interpolated to be applicable in the programming environment.

- The second step is to design the program interface and write the program code. In this stage the input and output data should be well known.

- The last stage is to run the program, check it for errors and get the final results.

At the end, the program will be verified to check if it is working properly, then it will be discussed to determine its positive and negative points. The details of creating a GUI programs in Matlab can be seen in $[11,12]$.

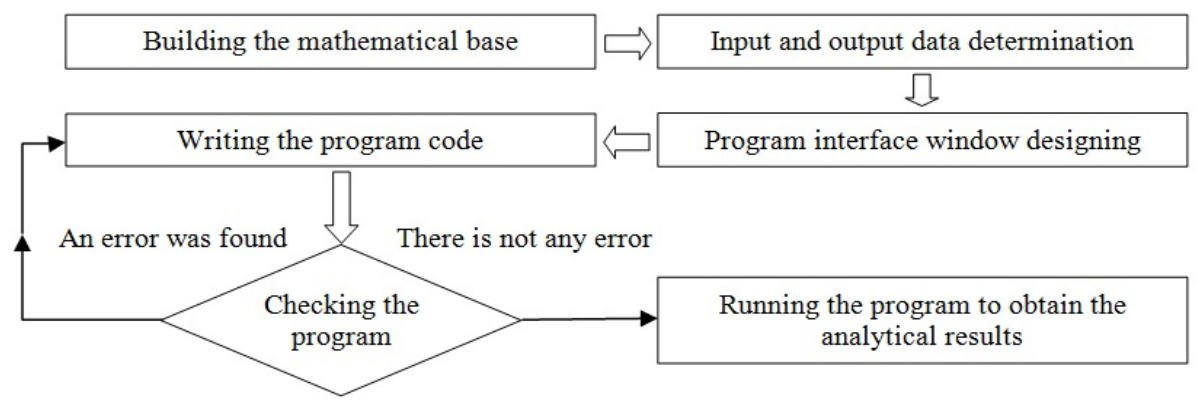

Fig.1 - Stages of creating the program.

\section{Determination of wheel-rail contact ellipse dimensions}

For the purpose of building the mathematical model of the studied problem, equations and tables will be introduced directly in their final forms. Some additional equations will be derived from the tables with the help of Matlab interpolation methods.

When two bodies are in contact, Hertz demonstrated that the contact surface is flat and has an elliptical shape if the following conditions are satisfied:

- Elastic behavior;

- Semi-infinite spaces;

- The body profile radii are constant and large in comparison with the contact zone dimensions [6].

The contact ellipse dimensions a and $b$, which can be seen in Fig.2, are calculated according to Hertz [5] using the following equations:

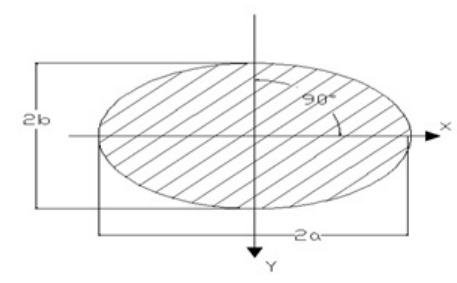

$$
a=m \cdot \sqrt[3]{\frac{3 N\left(1-\vartheta^{2}\right)}{E(A+B)}}
$$

Fig.2 - Contact ellipse semi-axis 


$$
b=n \cdot \sqrt[3]{\frac{3 N\left(1-\vartheta^{2}\right)}{E(A+B)}}
$$

Where:

$a$ is the contact ellipse semi-axis on longitudinal direction (mm);

$b$ is the contact ellipse semi-axis on transversal direction $(\mathrm{mm})$;

$m$ and $n$ are coefficients given by Hertz in table 1 .

Table 1

Hertz coefficients

\begin{tabular}{|c|c|c|c|c|c|c|c|c|c|}
\hline$\beta^{0}$ & 90 & 80 & 70 & 60 & 50 & 40 & 30 & 20 & 10 \\
\hline $\mathrm{m}$ & 1 & 1.128 & 1.284 & 1.486 & 1.754 & 2.136 & 2.731 & 3.778 & 6.612 \\
\hline $\mathrm{n}$ & 1 & 0.893 & 0.802 & 0.717 & 0.641 & 0.567 & 0.439 & 0.408 & 0.319 \\
\hline
\end{tabular}

Equations $m=f\left(\beta^{0}\right)$ and $n=f\left(\beta^{0}\right)$ are determined using Matlab. After the table values are introduced as matrices in Matlab, the curves which pass from points $\left(\beta^{0}, m\right)$ and $\left(\beta^{0}, n\right)$ are plotted. By using the Matlab plotting tools, the closest equations, which have the closest curves to the plotted ones, are found and can be written as the following:

$$
\begin{aligned}
& m=f\left(\beta^{0}\right)=5,930 \cdot 10^{-7} \beta^{4}-0,0001428 \beta^{3}+0,013817 \beta^{2}-0,57829 \beta+ \\
& 11,095
\end{aligned}
$$

With norm of residuals $=0.31292$;

$$
\begin{aligned}
& n=f\left(\beta^{0}\right)=1,7133 \cdot 10^{-8} \beta^{4}-3,3677 \cdot 10^{-6} \beta^{3}+0,00023584 \beta^{2}+ \\
& 0,0014623 \beta+0,28878
\end{aligned}
$$

With norm of residuals $=0.038332$. See [12] for details.

$\beta$ should be introduced in equations 3 and 4 in (degrees), and it can be obtained from:

$$
\beta=\cos ^{-1}[(A-B) /(A+B)]
$$

The calculation of $(\mathrm{A}+\mathrm{B})$ and $(\mathrm{A}-\mathrm{B})$ is dependent on the wheel-rail interaction situation:

In the case of a conic wheel profile (Fig.3-a), which is met usually with locomotive wheels, when $\rho_{r}=\infty$, we write:

$$
\begin{aligned}
& A+B=\left(\rho_{s}+r\right) /\left(r . \rho_{s}\right) \\
& A+B=\left(\rho_{s}+r\right) /\left(r . \rho_{s}\right)
\end{aligned}
$$

In the case of a worn wheel profile (Fig.3-b), which met usually with rail cars, when $\rho_{r}<0$, we write:

$$
\begin{aligned}
& A+B=\left[\left(\rho_{s}+r\right) /\left(r \cdot \rho_{s}\right)\right]- \\
& \left(1 / \rho_{r}\right) \quad(1 / \mathrm{mm}) \\
& A-B=\left[\left(\rho_{s}-r\right) /\left(r \cdot \rho_{s}\right)\right]+\left(1 / \rho_{r}\right) \quad(1 / \mathrm{mm})
\end{aligned}
$$

Where:

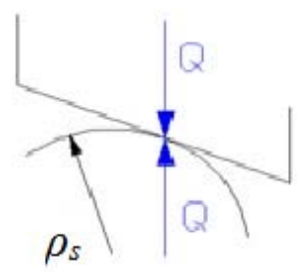

a

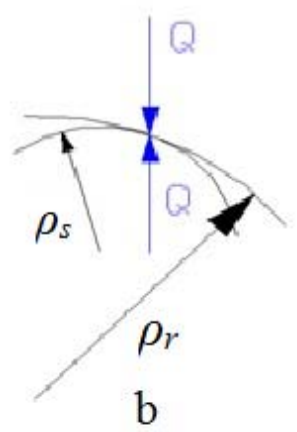

Fig.3 - Wheel-rail profiles interaction

$\rho_{s}:$ rail profile radius in the contact point $(\mathrm{mm})$;

$\rho_{r}$ : wheel profile radius in the contact point $(\mathrm{mm})$;

$r$ : the nominal radius of the wheel $(\mathrm{mm})$;

$N$ : vertical reaction force on the rails in the contact point and can be considered equals to the load on the wheel Q (N) if we assume that the contact is taking place at one single point. 
$N$ can be determined according to the maximum admissible load on each wheel which depends on the wheel radius, as it is recommended in [13] and can be seen in table 2.

Table 2

The variation of the maximum admissible load with wheel radius

\begin{tabular}{|c|c|c|c|c|c|c|c|c|}
\hline $\begin{array}{c}\text { Wheel radius } \\
(\mathrm{mm})\end{array}$ & 500 & 420 & 380 & 340 & 315 & 275 & 235 & 195 \\
\hline $\begin{array}{c}\text { Admissible } \\
\text { load } \\
\text { (N/wheel) }\end{array}$ & 100000 & 90000 & 80000 & 70000 & 60000 & 50000 & 37500 & 25000 \\
\hline
\end{tabular}

९: Poisson coefficient, usually considered 0.3 ;

E: Coefficient of elasticity or modulus of Young (MPa). E varies with temperature as shown in table 3, [5].

Table 3

Young's modulus variation with temperature

\begin{tabular}{|c|c|c|c|c|c|}
\hline Temperature: $\mathrm{t}\left(\mathrm{C}^{0}\right)$ & 100 & 200 & 300 & 400 & 500 \\
\hline $\mathrm{E} / \mathrm{E}_{20}$ & 0,98 & 0,95 & 0,91 & 0,85 & 0,70 \\
\hline
\end{tabular}

Using the same interpolation method which is used to approach the relations 4 and 5 , a relation $\mathrm{E} / \mathrm{E}_{20}=\mathrm{f}(\mathrm{t})$, which has a curve passes through the points mentioned in table 3, can be found. And we gain the following relation:

$$
E=\left(-6,7 \cdot 10^{-9} \cdot t^{3}+4,1 \cdot 10^{-6} \cdot t^{2}-0,0011 \cdot t+1,1\right) E_{20}
$$

For normal steel $\mathrm{E}_{20}=200(\mathrm{GPa})$.

\section{Normal pressure in the contact zone}

The maximum normal pressure between the wheel and the rail, which is assumed to be located in the center of the contact ellipse, can be calculated from the following equation:

$$
P_{\max }=3 Q /(2 \pi \cdot a \cdot b)
$$

The normal pressure distribution in the contact zone has a semi-elliptical shape. The following equation will be used in the program code to illustrate pressure distribution in the contact zone:

$$
P=P_{\max } \sqrt{1-(x / a)^{2}-(y / b)^{2}}
$$

Where $\mathrm{x}$ and $\mathrm{y}$ are the coordinates of the contact zone points measured from the original point, which is located in the contact ellipse center, on the longitudinal and transversal axes, respectively. $\mathrm{x}$ varies from $-\mathrm{a}$ to $+\mathrm{a}$, while $\mathrm{y}$ varies from $-\mathrm{b}$ to $+\mathrm{b}[5,6]$.

\section{A numerical application:}

For an introduced set of parameters with the values:

$\mathrm{r}=500(\mathrm{~mm}) ; \rho_{\mathrm{s}}=300(\mathrm{~mm})$; for locomotive $\rho_{\mathrm{r}}=\infty(\mathrm{mm}) ; \vartheta=0.3 ; \mathrm{E}_{20}=200000(\mathrm{MPa}) ;$

$\mathrm{t}=100\left({ }^{0} \mathrm{C}\right) ; \mathrm{N}=100000(\mathrm{~N})$ (the maximum admissible load),

we find that: $a=12.0916(\mathrm{~mm}), \mathrm{b}=7.6630(\mathrm{~mm})$, and the maximum normal pressure in the contact zone $\mathrm{P}_{\max }=515.561(\mathrm{MPa})$.

\section{Determination of friction coefficients between wheels and rails}

The proposed program calculates friction coefficients on the basis of three different theories. However, the slip velocities, for all these methods, will be calculated according to the equations presented by Kalker in [7]. 


\subsection{Slip velocity calculation}

On the straight lines when $\mathrm{R}>10000$ (m), we can calculate slip velocities with the following equations:

$$
\begin{array}{lc}
W_{e x}=\left|V \cdot(1-K)\left(1+\frac{\gamma}{r} \cdot y_{c}\right)\right| & - \text { On the external wheel }(\mathrm{m} / \mathrm{s}) ; \\
W_{i x}=\left|V \cdot(1-K)\left(1-\frac{\gamma}{r} \cdot y_{c}\right)\right| & \text { - On the internal wheel }(\mathrm{m} / \mathrm{s}) \\
W_{y}=\left|-\frac{R \cdot \alpha}{S} \cdot V\right| & (\mathrm{m} / \mathrm{s})
\end{array}
$$

While on the curved lines when $\mathrm{R}<10000(\mathrm{~m})$, we have:

$$
\begin{aligned}
& W_{e x}=\left|(e-\eta)(1-K \cdot R / S) \frac{V}{R}\right| ; \\
& W_{i x}=\left|-(e+\eta)(1-K \cdot R / S) \frac{V}{R}\right| ; \\
& W_{y}=\left|-\frac{R \cdot \alpha}{S} \cdot V\right|,
\end{aligned}
$$

where:

$$
\begin{aligned}
-\quad S & =\frac{e \cdot r}{\gamma \cdot y_{c}} \quad-\text { factor of suppleness; } \\
-\quad \eta & =\frac{(1-K)(S \cdot R)}{K \cdot R-S}
\end{aligned}
$$

The distance $\eta$ is obtained from the following equations:

$$
r /(K . R)=r_{r} /(R+\eta) \text { and } r / S=r_{r} /(S+\eta)
$$

$\mathrm{V}$ : locomotive speed $(\mathrm{m} / \mathrm{s})$;

$\mathrm{K}$ : is a coefficient related to the wheel set working regime:

$\mathrm{K}=1 \quad$ free wheel set;

$0 \leq \mathrm{K}<1 \quad$ in braking mode;

$1<\mathrm{K}<\infty \quad$ in traction mode.

e is the distance between wheels or the wheel set width ( $\mathrm{mm})$;

$\gamma$ equivalent conicity of wheel profile (rad);

$\mathrm{y}_{\mathrm{c}}$ wheel set mass center deviation from the rails central axis $(\mathrm{mm})$;

$\alpha$ yaw angle (rad).

\subsection{Kalker's method}

On the basis of Kalker's theory $[8,14]$, for the case of small creepages $(v=0.001 \ldots 0.0015)$, we can write:

$$
\begin{aligned}
& \tau_{x}=\chi_{x} \cdot v_{x} \\
& \tau_{y}=\chi_{y} \cdot v_{y}+\chi_{s} \cdot v_{s}
\end{aligned}
$$

where:

$$
\begin{aligned}
& \chi_{x}=G \cdot a \cdot b \cdot C_{11} / N \\
& \chi_{y}=G \cdot a \cdot b \cdot C_{22} / N \\
& \chi_{s}=G \cdot(a \cdot b)^{3 / 2} \cdot C_{23} / r \cdot N \\
& G=E /[2(1+v)] \text { Coefficient of transversal elasticity or shear modulus } \\
& \quad(\mathrm{MPa}) ;
\end{aligned}
$$


$\vartheta \approx 0,3 \quad$ Poisson's coefficient;

$E=f(t) \cdot E_{20}$ is calculated from the equation (10).

$\mathrm{C}_{11}, \mathrm{C}_{22}, \mathrm{C}_{23}$ are coefficients calculated by Kalker and have the values given in table 4 [7].

Table 4

Kalker's coefficients

\begin{tabular}{|c|c|c|c|}
\hline $\mathbf{a} / \mathbf{b}$ & $\mathbf{C}_{\mathbf{1 1}}$ & $\mathbf{C}_{\mathbf{2 2}}$ & $\mathbf{C}_{\mathbf{2 3}}$ \\
\hline 0,1 & 3,56 & 2,52 & 0,515 \\
\hline 0,2 & 3,61 & 2,64 & 0,637 \\
\hline 0,3 & 3,66 & 2,76 & 0,745 \\
\hline 0,4 & 3,74 & 2,90 & 0,850 \\
\hline 0,5 & 3,82 & 3,04 & 0,954 \\
\hline 0,6 & 3,92 & 3,17 & 1,06 \\
\hline 0,7 & 4,01 & 3,32 & 1,17 \\
\hline 0,8 & 4,10 & 3,46 & 1,28 \\
\hline 0,9 & 4,20 & 3,59 & 1,39 \\
\hline 1,0 & 4,31 & 3,73 & 1,50 \\
\hline
\end{tabular}

The relations between the coefficients $\mathrm{C}_{11}, \mathrm{C}_{22}, \mathrm{C}_{23}$ and the ratio a/b can be determined using Matlab, and we get:

$$
C_{11}=0,32955(a / b)^{2}+0,48538(a / b)+3,4992
$$

with norm of residuals $=0.024181$;

$$
C_{22}=0,90909(a / b)^{2}+1,2594(a / b)+2,3853
$$

with norm of residuals $=0.020331$;

$$
C_{23}=1,0835(a / b)+0,4142
$$

with norm of residuals $=0.013002$.

The creepage coefficients $v_{x}, v_{y}, v_{s}$ are non-dimensional factors, and are equal to the ratio of slip velocities to train net speed:

$$
\begin{array}{ll}
v_{x}=W_{x} / V & \text { - on the longitudinal direction; } \\
v_{y}=W_{y} / V & \text { - on the transversal direction; } \\
v_{s}=r \cdot W_{s} / V & \text { - rotary creepage around the normal axis z. }
\end{array}
$$

If creepage coefficients are greater than $0.0015\left(v_{\mathrm{x}}, v_{\mathrm{y}}\right.$ or $\left.v_{s}>0.0015\right)$, then the following equations should be used:

$$
\tau_{x, y}=\left[\left(\frac{1}{\mu}\right)^{n}+\left(\frac{1}{\chi_{x, y} \cdot v_{x, y}}\right)^{n}\right]^{-1 / n}
$$

where:

$$
\begin{aligned}
& -n=2,2+0,05 \cdot Q \\
& -\mu=0,36-0,02425 \cdot Q+0,001 \cdot Q^{2} \quad \text { - adhession coefficient }
\end{aligned}
$$

- $\mathrm{Q}$ is the load on the wheel (we can consider that $Q \approx N$ ).

\subsection{Chartet method}

The second method of friction coefficients determination is based on Chartet approximation. The relations which characterize this method are given by Chartet in [9] and they can be written as the following:

where:

$$
\tau=\sqrt{\tau_{x}^{2}+\tau_{y}^{2}}
$$

$$
\begin{aligned}
\tau_{x} & =\frac{\mu \cdot v_{x}}{\left[(\mu / \chi)^{2}+v^{2}\right]^{1 / 2}} \\
\tau_{y} & =\frac{\mu \cdot v_{y}}{\left[(\mu / \chi)^{2}+v^{2}\right]^{1 / 2}}
\end{aligned}
$$




$$
\begin{aligned}
& v=\sqrt{v_{x}^{2}+v_{y}^{2}}: v_{x}=W_{x} / V, v_{y}=W_{y} / V \\
& \chi=(G \cdot a \cdot b / N)\left[\left(C_{11}+C_{22}\right) / 2\right] \\
& G=\frac{1}{2} \cdot \frac{E}{1+\vartheta} \text { shear modulus, calculated with the equation (26) } \\
& \mu \text { : adhession coefficient, calculated with the equation (35). }
\end{aligned}
$$

\subsection{Polach method}

The third method of friction coefficients calculation is based on the experimental results obtained by Polach and presented in [10]. Polach studied the influence of weather conditions on the contact zone characteristics and introduced new equations, which take these climate conditions into consideration. The following equations allow us to calculate friction coefficients for dry and wet rails:

$$
\tau_{x, y}=\tau_{0}\left[(1-A) e^{-B \omega_{x, y}}+A\right]
$$

Where $\mathrm{A}$ is the ratio of limit friction coefficient at infinity slip velocity $\tau_{\infty}$ to maximum friction coefficient $\tau_{0}$, i.e.,

$$
A=\tau_{\infty} / \tau_{0}
$$

B: coefficient of exponential friction decrease $(\mathrm{s} / \mathrm{m})$.

The values of typical model parameters for dry and wet rails are given in table 5 .

Typical model parameters for dry and wet conditions of real wheel-rail contact

\begin{tabular}{|c|c|c|}
\hline \multirow{2}{*}{ Model parameter } & \multicolumn{2}{|c|}{ Wheel -rail condition } \\
\cline { 2 - 3 } & Dry & Wet \\
\hline$\tau_{0}$ & 0.55 & 0.30 \\
\hline $\mathrm{A}$ & 0.40 & 0.40 \\
\hline $\mathrm{B}(\mathrm{s} / \mathrm{m})$ & 0.60 & 0.20 \\
\hline
\end{tabular}

We mention that Polach introduced reduction factors to these friction coefficients during the calculation of the creep forces.

\section{A numerical application:}

For an introduced set of parameters with the values:

$\mathrm{V}=20(\mathrm{~m} / \mathrm{s}), \mathrm{R}=2000(\mathrm{~m}), \alpha=0.2(\mathrm{rad}), \mathrm{e}=1500(\mathrm{~mm}), \mathrm{y}_{\mathrm{c}}=4(\mathrm{~mm}), \gamma=60^{0}, \mathrm{~K}=50$.

with 'a' and 'b' already obtained: $a=12.0916(\mathrm{~mm}), \mathrm{b}=7.66298(\mathrm{~mm})$,

we find the following coefficients of friction:

(Kalker): $\tau_{\mathrm{x}}=0.2175, \tau_{\mathrm{y}}=0.2147, \tau_{\text {total }}=0.3056$;

(Chartet): $\tau_{\mathrm{x}}=0.2173, \tau_{\mathrm{y}}=0.01 \quad, \tau_{\text {total }}=0.2175$;

(Polach): $\quad$ On dry rails: $\tau_{\mathrm{x}}=0.4033, \tau_{\mathrm{y}}=0.5413, \tau_{\text {total }}=0.6750$;

On wet rails: $\tau_{\mathrm{x}}=0.2680, \tau_{\mathrm{y}}=0.2984, \tau_{\text {total }}=0.4011$.

It can be noticed that the values of friction coefficients calculated with Polach equations are high, this is due to the constantly introduced values for the parameters A, B and $\tau_{0}$. Therefore, the equations (41) and (42) do not take all the external conditions into consideration, such as temperature, etc. However, the calculation of the creep forces at the adhesion limit includes, as suggested in $[10,15]$, the introduction of two reduction factors: $\mathrm{k}_{\mathrm{A}}$ in the area of adhesion and $\mathrm{k}_{\mathrm{s}}$ in the area of slip.

\section{Program description and working method}

After the mathematical base is completely built, the equations presented above can be introduced into the program code. The program interface was designed considering the input and output parameters. 
Finally, the program code was written with the help of the information and instructions provided in $[11,16,17]$. The created program is composed of two windows. The first program window, as seen in Fig.4, is divided into three sections. The first one, input 1 section, is where the general parameters are introduced. Checking the box "use the max. admissible load" will automatically calculate the maximum admissible load value on the wheel and set the reaction force value ' $\mathrm{N}$ ' to this value. The second section is where the contact ellipse dimensions are calculated and visualized. The "Calculate" button will display ' $a$ ' and ' $b$ ' values and plot the contact ellipse. The "Clear" button is used to clear the plotted ellipse. Otherwise, the previous contact ellipse plot will remain with the current one, allowing us to compare the difference between the plotted contact ellipses, as seen in Fig.6. The third section has the role of calculating the maximum pressure and illustrating the pressure distribution in the contact zone. On the top of this window the user can choose if the studied vehicle is a locomotive or a railway car. "Reset to default" button on the bottom of this window will set the input parameters values to the values denoted in Fig.4.

The second program window, as seen in Fig.5, is divided into four sections. The first one from the top is where the necessary parameters for contact coefficients calculation are introduced. The "Calculate" button in this window will display the results of the friction coefficients calculation. The program can be closed from any window by clicking the "Exit" button.

An additional useful feature is demonstrated in the program ability to alert the user if one or more of the input parameters are out of the reasonable range, (see Fig.6).

The symbols which are used in the program windows are denoted in table 6. Here we mention that the "Calculate" button in the second window (for friction coefficient calculation) will not give any result if the "Calculate" button in the second section of the first window is not clicked (i.e. contact ellipse calculation button). That is because the calculation of the friction coefficients is dependent on the contact ellipse dimensions. The results of a typical model calculation are shown in Fig.4 and Fig.5.

Table 6

The symbols used in the program

\begin{tabular}{|c|c|c|c|}
\hline \multicolumn{2}{|r|}{ First window } & \multicolumn{2}{|r|}{ Second window } \\
\hline Symbol & Definition & Symbol & Definition \\
\hline $\mathrm{r}$ & Wheel nominal radius & $\mathrm{e}$ & $\begin{array}{c}\text { The distance between the nominal plans } \\
\text { of the left and right wheels (Wheel set } \\
\text { gauge) }\end{array}$ \\
\hline Ros & $\begin{array}{l}\text { The radius of the rail profile in the } \\
\text { contact point }\end{array}$ & $\mathrm{R}$ & $\begin{array}{l}\text { The path curve radius which the } \\
\text { locomotive center of mass is moving on }\end{array}$ \\
\hline Ror & $\begin{array}{l}\text { The radius of the wheel profile in the } \\
\text { contact point }\end{array}$ & Gamma & $\begin{array}{l}\text { Wheel profile inclination angle with the } \\
\text { horizontal plan at the contact point } \\
\text { (Conicity) }\end{array}$ \\
\hline $\begin{array}{c}\text { Poisson's } \\
\text { v }\end{array}$ & Poisson factor & $\mathrm{V}$ & Train speed \\
\hline E20 & $\begin{array}{l}\text { Young modulus of the wheel/rail } \\
\text { material at } 20^{\circ} \mathrm{C}\end{array}$ & Alfa & Yaw angle \\
\hline $\mathrm{T}$ & Temperature & $\mathrm{Yc}$ & The lateral displacement or shift \\
\hline $\mathrm{N}$ & Rail reaction force in the contact point & $\mathrm{K}$ & $\begin{array}{l}\text { Factor of working regime of the rail } \\
\text { vehicle }\end{array}$ \\
\hline $\mathrm{a}$ & $\begin{array}{l}\text { contact ellipse semi-axis in the } \\
\text { longitudinal direction }\end{array}$ & $\begin{array}{l}\text { Taox, } \\
\text { Taoy }\end{array}$ & $\begin{array}{l}\text { Friction coefficients in the longitudinal } \\
\text { and transversal directions, respectively }\end{array}$ \\
\hline $\mathrm{b}$ & $\begin{array}{l}\text { contact ellipse semi-axis in the } \\
\text { transversal direction }\end{array}$ & Tao total & Total friction coefficient \\
\hline
\end{tabular}


- Vehicle type

Choose an option, please! () Locomotive Railways car

\begin{tabular}{|c|c|c|c|c|c|c|c|c|}
\hline \multicolumn{3}{|c|}{ Geometric conditions - } & \multicolumn{2}{|c|}{-Material properties - } & & \multicolumn{3}{|c|}{ - Initial conditions- } \\
\hline $\mathbf{r}$ & 500 & \multirow{3}{*}{$\begin{array}{l}\mathrm{mm} \\
\mathrm{mm} \\
\mathrm{mm}\end{array}$} & Poisson's v & 0.3 & \multirow{3}{*}{$\mathrm{MPa}$} & $\mathrm{T}$ & 100 & Celsius \\
\hline Ros & 300 & & \multirow{2}{*}{ E20 } & \multirow{2}{*}{200000} & & $N$ & 78000 & Newton \\
\hline Ror & 500 & & & & & \multicolumn{3}{|c|}{$\square$ Use the max. admisible load } \\
\hline
\end{tabular}

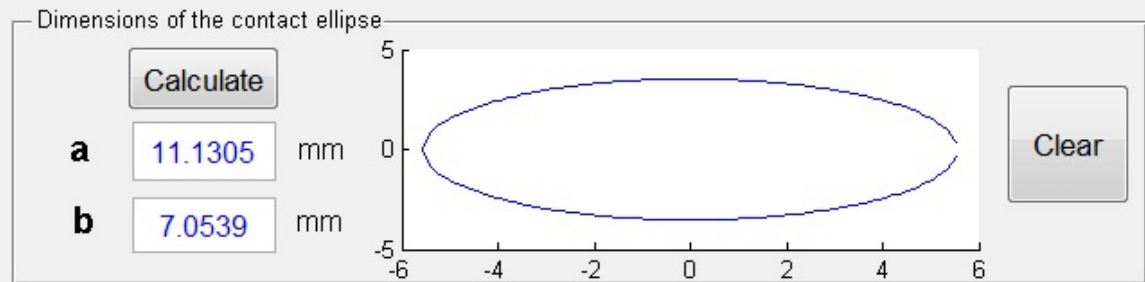

- Pressure in the contact zone-

\section{Calculate}

Maximum pressure

$474.583 \mathrm{MPa}$

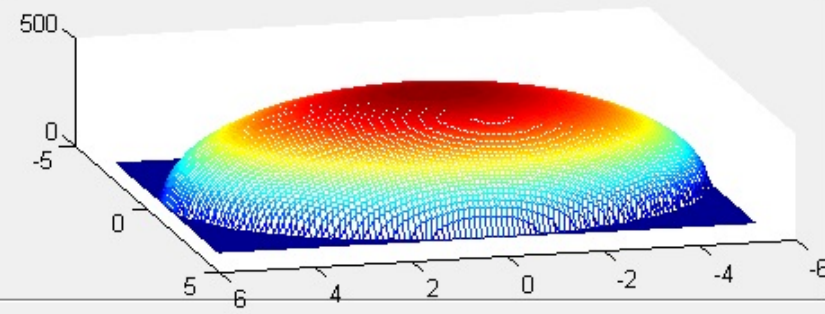

Exit

Reset to defualt

Calculate friction coefficients

Fig.4 - Contact ellipse dimensions and pressure distribution in the first program window.

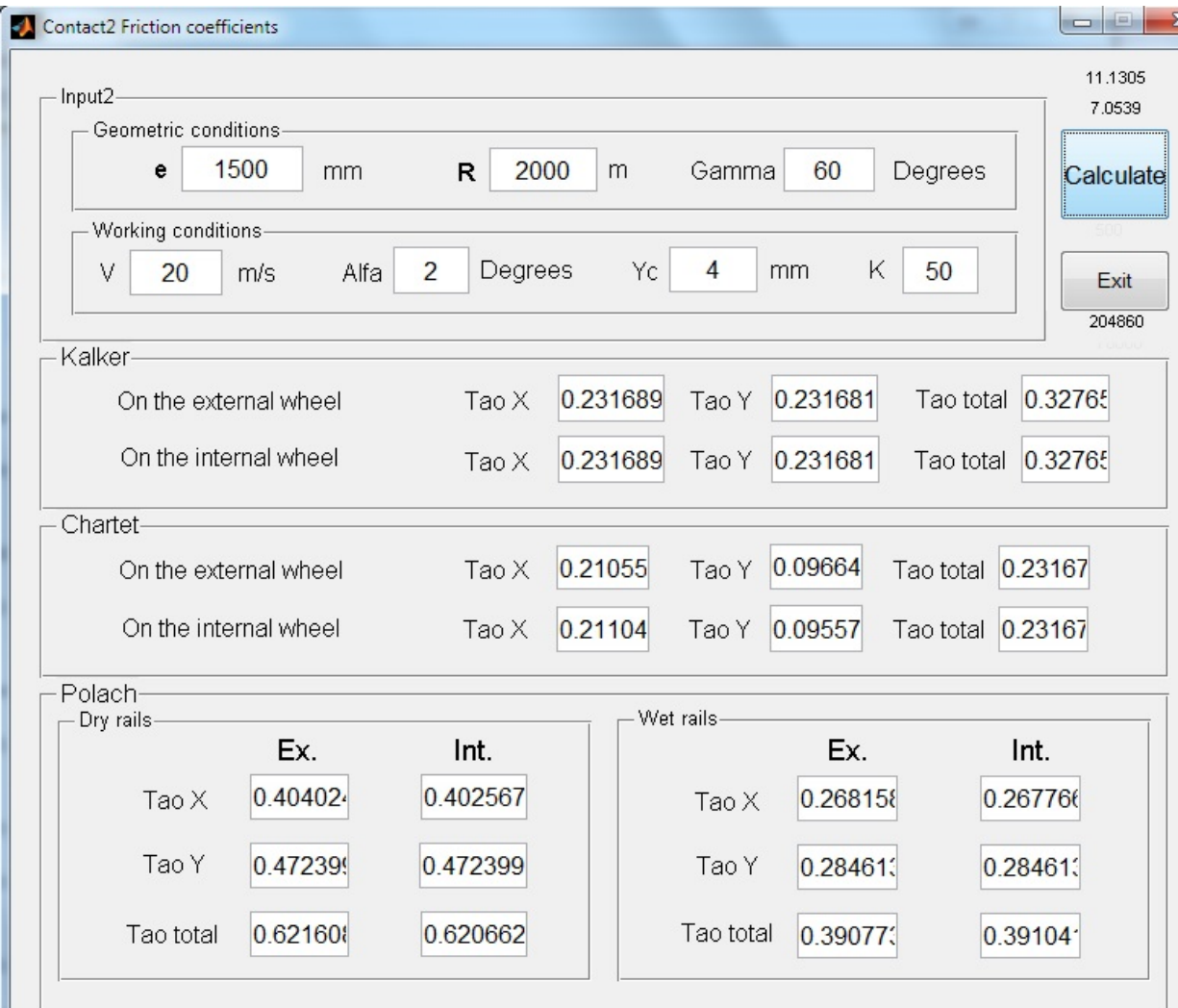

Fig.5 - Friction coefficients calculation in the second program window. 

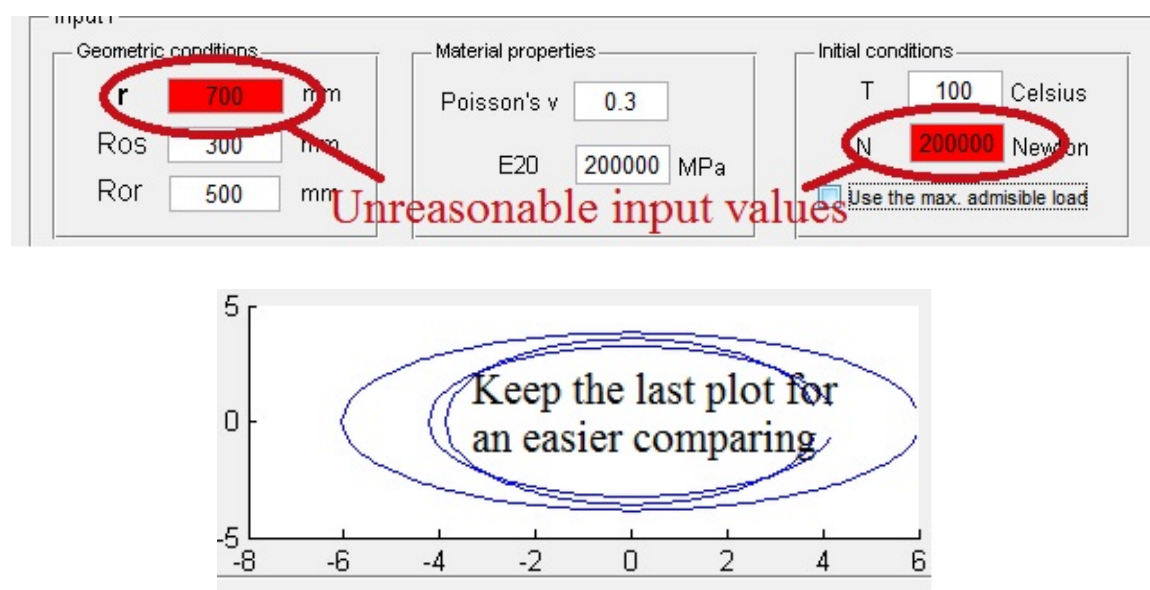

Fig.6 - Some of the program additional features

\section{Analyzing the temperature influence}

As a practical application of this program, the temperature effect on the contact ellipse dimensions and the maximum pressure in the contact zone can be easily studied. Table 7 shows how temperature affects some of the contact properties. Only the temperature will be changed, while the rest of the parameters will be kept constant having the values shown in Fig.4.

Table 7

Temperature influence on wheel-rail contact

\begin{tabular}{|c|c|c|c|}
\hline Temperature & $\mathrm{a}(\mathrm{mm})$ & $\mathrm{b}(\mathrm{mm})$ & $\begin{array}{c}\text { Maximum pressure } \\
(\mathrm{MPa})\end{array}$ \\
\hline-50 & 10.66 & 6.76 & 517.43 \\
\hline 0 & 10.87 & 6.89 & 497.6 \\
\hline 50 & 11.02 & 6.99 & 483.84 \\
\hline 100 & 11.13 & 7.05 & 474.58 \\
\hline 150 & 11.20 & 7.10 & 468.49 \\
\hline 200 & 11.26 & 7.13 & 464.05 \\
\hline
\end{tabular}

We can notice from table 7 that the dimensions $a$ and $b$ increase when the temperature is increased. On the other hand, the maximum pressure will decrease when the temperature is increased. However, the friction coefficients $\tau_{y}, \tau_{x}$ and $\tau_{\text {total }}$ will slightly decrease when the temperature is increased. This can be explained because the friction coefficients are not related only to the contact ellipse dimensions, but also to the ratio a/b. It is known that the adhesion between two surfaces is produced by the micro-protrusions which weld with the microprotrusions on the other surface. This decreasing in the friction coefficient can be explained by the fact that when temperature increases, the micro-welding points suffer from a weakening effect, therefore, the surfaces in contact will tend to separate more easily. This conclusion is coincident with the results obtained by O. Polach in [10].

\section{Speed influence on friction coefficients}

We can study the train speed effect on the contact properties, as well, as another practical application of the present program. The results of calculating the friction coefficients using Polach equations are shown in table 8. 
The influence of the train speed on the friction coefficients

\begin{tabular}{|c|c|c|c|c|c|c|c|c|}
\hline \multirow{2}{*}{\multicolumn{2}{|c|}{$\begin{array}{l}\text { Calculation } \\
\text { method }\end{array}$}} & Speed $(\mathrm{m} / \mathrm{s})$ & \multirow{2}{*}{10} & \multirow{2}{*}{20} & \multirow{2}{*}{30} & \multirow{2}{*}{40} & \multirow{2}{*}{50} & \multirow{2}{*}{60} \\
\hline & & Parameter & & & & & & \\
\hline \multirow{6}{*}{ Polach } & \multirow{3}{*}{$\begin{array}{l}\text { Dry } \\
\text { rails }\end{array}$} & $\tau_{x}$ & 0.466 & 0.403 & 0.357 & 0.322 & 0.296 & 0.277 \\
\hline & & $\tau_{y}$ & 0.509 & 0.472 & 0.441 & 0.413 & 0.389 & 0.368 \\
\hline & & $\tau_{\text {total }}$ & 0.690 & 0.621 & 0.567 & 0.524 & 0.489 & 0.460 \\
\hline & \multirow{3}{*}{$\begin{array}{l}\text { Wet } \\
\text { rails }\end{array}$} & $\tau_{x}$ & 0.283 & 0.268 & 0.254 & 0.242 & 0.230 & 0.220 \\
\hline & & $\tau_{y}$ & 0.292 & 0.285 & 0.277 & 0.271 & 0.264 & 0.258 \\
\hline & & $\tau_{\text {total }}$ & 0.407 & 0.391 & 0.376 & 0.363 & 0.350 & 0.339 \\
\hline
\end{tabular}

We can notice in table 8 that friction coefficients decrease with speed increase.

This can be explained due to the exponential relation between slip velocity and friction coefficients, which can be observed in the equation (41). The program results showed that friction coefficients which are calculated within Chartet and Kalker methods are independent of the train speed. By analyzing Chartet and Kalker's equations, we notice that speed is introduced in the equations of slip velocities (13-18) in the numerator while speed is introduced in the equations $(30,31,32$ and 39) in the denominator. As a result, the speed effect is eliminated from these methods.

\section{Conclusions}

The first practical result of this work paper is the created program. The equations and instructions which are provided in this paper allow other researchers to create their own programs to calculate contact zone properties. By the determination of the equations which are involved in the friction coefficient calculation process, the parameters which affects friction coefficients and, as a result, locomotive traction process, were specified. The created program determines exactly how much each parameter affects the friction coefficient. After the program had been completely built, two main parameters were tested. The calculations which concerned of temperature influence showed that temperature increase will lead to contact ellipse dimension increase. On the other hand, the maximum pressure will decrease when temperature is increased. These calculations showed also that the temperature effect on friction coefficients is limited. Particularly, temperature increasing will cause a very small decreasing of the friction coefficients. Friction coefficients calculated with the equations (41) and (42) will remain unchanged with temperature variation. That is because the parameters $\mathrm{A}, \mathrm{B}$ and $\tau_{0}$ were considered constant to simplify the calculation. Practically, these parameters will change when the temperature is changed. The second analyzed parameter is the train speed. The results gained from the program showed that the speed effect on the contact zone characteristics is very small except for friction coefficients which are calculated with Polach equations. In reality, as it was proved in [10], friction coefficients decrease within non-linear relation with speed increasing. Here we mention that train speed doesn't change contact ellipse dimensions, but it changes the areas of slipping and adhesion inside the contact ellipse. More details about this phenomenon are presented in $[10,15,18]$.

The created program is a very useful tool to analyze the parameter influence on the characteristics of the contact between rails and wheels. It gives quick results for the complicated calculations associated with friction coefficient determination. When the experimental results are available, program users can easily develop the theoretical equations presented in this paper by observing points of discordance between the experimental and theoretical results. Above all, instead of the limited number of parameters modifying at the laboratory experiments, the program allows us to easily make huge numbers of parameters modifying within no time. The results which can be obtained from the program - because of their huge number - can't be included in this work paper. Nevertheless, the program has some negative points. During the building of the mathematical model of the program, some approximations have been used and they present a small amount of errors in 
calculation. For instance, equations $(3,4,10,27,28$ and 29) have small values of norm of residuals. Another disadvantage of the presented program is due to Matlab insufficient accuracy which accompanies the calculations of extremely tiny numbers. In addition, it is noticed that the obtained coefficients have high values compared with the values obtained experimentally in reality and presented in $[10,18,19,20]$. In fact, this is because the adopted equations, while creating the program, do not take into consideration all of the surrounding atmospheric conditions like humidity, temperature and the existence of pollutant particles in the contact point during the experiment. We also mention that more developed approximation methods are reached in the last few years and may give results closer to the real ones, as can be seen in $[15,18,19,20]$.

The dynamic structure of the program permits its development to reach more accurate results and to reduce the researchers' efforts. A prospective tendency of the program improvement may be concerned of registering the contact zone properties variation in the database sheets when one or more of the input parameters are modified. Thus, tables, like table 7 and table 8 , will be automatically created by the program itself. Therefore, it is clear that the program presented in this paper will become, with a few more research efforts, a bigger simulation environment.

\section{References}

[1] Vollebregt, E.A.H. \& Kalker, J.J. (2013). CONTACT: Vollebregt \& Kalker's rolling and sliding contact model. Retrieved February 16, 2014, from http://www.kalkersoftware.org/

[2] Vollebregt, E.A.H. (2013). User guide for CONTACT, Vollebregt \& Kalker's rolling and sliding contact model. Delft: Vortech Computing.

[3] Vollebregt E.A.H. (2010). User Guide for Contact, J.J.Kalker's Variational Contact Model, Delft: VORtech Computing.

[4] Jong Kim. (2012, April). Hertz's contact ellipse between rail and wheel. Retrieved February 16, 2014, from http://www.mathworks.com/matlabcentral/fileexchange/36068-hertzs-contact-ellipse-between-rail-andwheel/content/contact ellipse calculator.m

[5] Sebeșan, I. (2011). Dynamics of railway vehicles (Dinamica vehiculelor feroviare). Bucharest: Matrixrom.

[6] Ayasse, J.B. (2006). Wheel-rail contact. In Iwnicki, S. (Eds.), Handbook of railway vehicle dynamics (pp. 85120). CRC Press, Taylor \& Francis group. Retrieved July 07, 2013, from CRC Press link: http://www.crcpress.com/product/isbn/9780849333217.

[7] Kalker, J.J. (1967). On the rolling contact of two elastic bodies in the presence of dry friction, $\mathrm{PhD}$. Thesis. University of Technology. Delft, Netherlands.

[8] Kalker, J.J. (1967). A strip theory for rolling with slip and spin. Mechanics, Series B,70. (pp. 10-62). Amsterdam: Koninklijke Nederlandse Akademie van Wetenschappen.

[9] Chartet, M. (1950). La théorie statique du déraillement d'un èssieu. In Revue générale des chimen de fer, 3 August, s. 365. Paris. RGCF. (In French).

[10] Polach, O. (2005, March). Creep Forces in Simulation of Traction Vehicles Running On Adhesion Limit. Wear, Volume 258 (Issues 7-8), 992-1000. Retrieved July 23, 2010, from Sciencedirect database on the World Wide Web: www.sciencedirect.com. DOI: 10.1016/j.wear.2004.03.046.

[11] The MathWorks, Inc. (2012, March). MATLAB: Creating graphical user interface, The MathWorks, Inc.

[12] Knight, A. (2000). Basics of Matlab and Beyond. London, Washington D.C.: Chapman \& Hall/CRC.

[13]ETF: Railway Technical Publications. (2004, May). Trailing stock: Wheels and wheelsets, conditions concerning the use of wheels of various diameters. UIC 510-2. France.

[14] Kalker, J.J. (1982). A fast algorithm for the simplified theory of rolling contact, Vehicle System Dynamics: International journal of vehicle mechanics and mobility, 11(1), 1-13. DOI: 10.1080/00423118208968684.

[15] Nielsen, J.B. (1998). New Developments in the Theory of Wheel/Rail Contact Mechanics. PhD. Thesis, Informatics and mathematical modeling, Tech. Univ. of Denmark, Lyngby.

[16] ${ }^{* * *}$ Matlab Official Website: http://www.mathworks.com/.

[17] Michel R. Hatch. (2001). Vibration Simulation Using MATLAB and ANSYS. Boca Raton, London, New York, Washington D.C.: Chapman \& Hall/CRC.

[18] Steenbergen M. (2006). Modeling of Wheels and Rails Discontinuities in Dynamic Wheel-Rail Contact Analysis. Vehicle System Dynamics: International journal of vehicle mechanics and mobility, 44 (10), 763-787. DOI: $10.1080 / 00423110600648535$.

[19] Hou, K., Kalousek, J. \& Dong, R. (2003, October). A Dynamic Model for an Asymmetrical Vehicle/Track System. Journal of Sound and Vibration, 267 (3), 591-604. DOI: 10.1016/s0022-46X(03)00726-0.

[20] Kabo E., Nielsen J.C.O. \& Ekberg A. (2006). Prediction of Dynamic Train-Track Interaction and subsequent material deterioration in the presence of insulated rail joints. International journal of vehicle mechanics and mobility, 44(1), 718-729. DOI: 10.1080/00423110600885715. 